\title{
Identification and Characterization of a Loquat Aneuploid with Novel Leaf Phenotypes
}

\author{
Jiangbo Dang, Tingrong Wu, Guolu Liang, Di Wu, Qiao He, \\ and Qigao Guo ${ }^{1}$ \\ College of Horticulture and Landscape, Southwest University, No. 2 \\ Tiansheng Road, Beibei District, Chongqing, 400715, China
}

Additional index words. chromosome, leaf, palisade mesophyll, chlorophyll, net photosynthetic rates

\begin{abstract}
A loquat (Eriobotrya japonica) seedling obtained from an open-pollinated triploid variety 'Wuheguoyu' $(2 n=3 x=51)$ was verified as aneuploid and designated H39. It was shown to have five extra chromosome copies $(2 n=39)$ compared with the diploid plant $(2 n=2 x=34)$, one additional copy each for the $2 \mathrm{nd}, 4 \mathrm{th}, 7 \mathrm{th}, 9$ th, and 11th chromosomes. A number of novel features of leaf morphology was observed for $\mathrm{H39}$ in comparison with 'Ruantiaobaisha' ( $2 x$, female progenitor) and 'Wuheguoyu' ( $3 x$, female parent), including increased leaf width, reduced leaf thickness, and narrowed palisade mesophyll and wax coat. Total chlorophyll content in unit area of $\mathrm{H39}$ leaves was close to or slightly less than the diploid and triploid parent lines. Chlorophyll content in unit mass showed the opposite trend, with $\mathrm{H3} 9$ having higher amount than the $2 x$ and $3 x$. As we expected, H39 had the lowest net photosynthetic rates among the three lines. Furthermore, 8-month-old scions of $\mathrm{H3} 9$ grew more slowly than those of the diploid and triploid lines, especially in plant height, which was much reduced $(P<0.01)$. These results indicated that the aneuploid $\mathrm{H39}$ was a potential germplasm for breeding dwarfing loquat rootstock or interstock.
\end{abstract}

Aneuploid is defined as individuals with one or multiple incomplete chromosome sets in the cells. Aneuploid occurs naturally in some plants such as Phalaenopsis (Zhuang et al., 2007), and is frequently found in interploid hybridization, especially in crosses involving a triploid (Ezura et al., 1994; Henry et al., 2009; Vogt and Rowe, 2011). Aneuploid has also been reported in some fruit trees, such as guava (Mohammed, 1974), apple (Chagné et al., 2015; Zhang and Sungmin, 2009), pear (Simard et al., 2011), citrus (Yasuda et al., 2010), grapevine (Park et al., 1999), and a few others (Badenes and Byrne, 2012).

Because of the abnormal chromosome numbers, aneuploids often exhibit weak vigor and consequently, few aneuploids thrive in nature. However, aneuploid plants can have some distinctive phenotypic traits that could be useful in breeding. Henry et al. (2005) reported that aneuploid individuals of Arabidopsis thaliana exhibited diverse phenotypes affecting a wide variety of traits, such as altered leaf color and shape, dwarfism ranging from subtle to extreme, and changes in flowering time.

Received for publication 27 Dec. 2018. Accepted for publication 8 Mar. 2019.

This research was supported by a project of Chongqing Science and Technology Commission (cstc2018jscx-mszdX0054) and Chinese Fundamental Research Funds for the Central Universities (XDJK2019AA001).

We thank Prof. Mingbo Wang from CSIRO Agriculture and Food for re-editing our manuscript.

${ }^{1}$ Corresponding author. E-mail: qgguo@126.com.
Some other specific traits were also found to be associated with the loss or gain of some chromosomes. Therefore, aneuploid plants can potentially be used to locate genes on the chromosome associated with specific traits (Henry et al., 2010a, 2010b).

Only a few studies focused on phenotypic traits of aneuploid fruit trees. Zhang and Park (2010) reported that aneuploid apple trees were smaller than the diploid trees in height and width of tree, in leaf size, and in weight and size of fruits. In addition, the fruits of almost all the aneuploid plants had higher sugar contents than those of the diploid, and nearly half of the aneuploid fruits were firmer than the diploid. Simard et al. (2011) demonstrated that dwarfing in Pyrus is linked with an aneuploid chromosomal structure found in hybrids between a Pyrus nivalis triploid genotype and a diploid one of the Pyrus species.

Aneuploids have also been observed in loquat (Kikuchi et al., 2014), but there have been no reports on the characteristics of these plants. We have established an aneuploid loquat line of 6 years old named H39, initially derived from a triploid loquat cultivar Wuheguoyu trough open-pollination. It displays some distinctive traits, especially the thin leaf character. In the present study we characterized the karyotype of the aneuploid loquat, and examined its leaf morphology and photosynthetic characteristics.

\section{Materials and Methods}

Plant materials. H39 was an open-pollinated daughter seedling of the triploid loquat cultivar Wuheguoyu $(2 n=3 x=51)$. 'Wuheguoyu' was derived from openpollinated progeny of the diploid cultivar Ruantiaobaisha $(2 n=2 x=34)$, which was widely cultivated in east and south China. Adult trees of H39, 'Wuheguoyu', and 'Ruantiaobaisha' were planted in polyploid loquat germplasm nursery of Southwest University (Beibei District, Chongqing, China). All of these trees were 5 to 6 years old. Grafted seedlings of H39, 'Wuheguoyu', and 'Ruantiaobaisha' were obtained by grafting them as scions onto 2-year-old rootstocks in the middle of Mar. 2018. All scions were excised from vigorous summer shoots of adult trees.

Chromosome preparation and karyotype analysis. Chromosomes at mitotic metaphase were prepared from stem tip materials according to methods reported by Chen et al. (1979). First, stem tips of $\approx 1 \mathrm{~cm}$ long were cut from spring shoots around the trees, immersed in $0.002 \mathrm{~mol} / \mathrm{L} 8$-hydroxyquinoline for $4 \mathrm{~h}$, and fixed in Carnoy's solution (methyl alcohol:acetic acid $=3: 1$ ) overnight. Then, apical meristems were isolated, rinsed in deionized water, and incubated in mixed enzyme solution containing 3\% cellulose (SCR, Shanghai, China) and $0.3 \%$ pectinase (Yakult, Japan). After $3.5 \mathrm{~h}$, the enzyme solution was removed, and the apical meristems were gently rinsed, and placed in Carnoy's solution. At last, apical meristems were dispersed on slides with tweezers and dried over the flame of an alcohol burner. Chromosomes were colorized with $5 \%$ Giemsa stain, dried in air, and visualized under a microscope (Olympus, Tokyo, Japan). Photographs were taken by using a chargecoupled device camera. Spreads with unfolded and nonoverlapping chromosomes were used to karyotype analysis.

Morphology observation on leaves. Leaf length and width of adult trees of all tree lines were measured. Biomasses in unit area of three lines were also measured.

Anatomic observation on leaves. Samples of leaves from adult trees of all tree lines were taken at the level of the third internode of the current-year spring shoots (from the top). All subsamples $(\approx 1 \times 3 \mathrm{~cm})$ for sectioning were picked from the middle region of each fresh leaves. Samples were fixed in FAA ( $95 \%$ ethanol/glacial acetic acid/formalin $/$ distilled water $=10 / 1 / 2 / 7)$, dehydrated in ethanol series $(50 \%, 70 \%, 80 \%, 95 \%$, and $100 \%$ ), and embedded in paraffin. Cross sections $8-\mu \mathrm{m}$-thick were stained with safranin $\mathrm{O}$-fast green, and visualized under a microscope (Olympus). Photographs were taken using a charge-coupled device camera. Thickness of wax coats, epidermis cells, palisade mesophylls, and spongy mesophyll were measured.

Growth measurement of current-year grafted scions. Height, stem thickness, internode length, leaf length, and leaf width of grafted scions of the tree lines were measured on grafted seedlings ( 8 months old). The leaves on middle shoots of the scions were used for the measurements.

Chlorophyll content determinations. The third leaves (from the top) on the current-year 
spring shoots of adult trees and the fifth leaves (from the graft union) of the scions on the grafted seedlings were used to determine chlorophyll contents. Approximately $0.1 \mathrm{~g}$ fresh leaf segments (excluding main veins) were immersed in $10 \mathrm{~mL} 80 \%$ acetone for $48 \mathrm{~h}$ in the dark $\left(25^{\circ} \mathrm{C}\right)$. Absorbance of the extract was analyzed at $470 \mathrm{~nm}, 646 \mathrm{~nm}$, and $663 \mathrm{~nm}$. Contents of chlorophyll a, chlorophyll b, carotenoid, and total chlorophyll in unit area $\left(\mathrm{cm}^{2}\right)$ and unit mass $(\mathrm{g})$ were calculated based on formulas presented by Lichtenthaler (1987).

Net photosynthetic rate measurements. Net photosynthetic rates of adult trees and the scions on the grafted seedlings were measured with portable photosynthesis system Li-6400 (LI-COR Inc., Lincoln, NE) twice in the morning (10:00-11:00) on the Oct. $10\left(25^{\circ} \mathrm{C}\right)$ and 18 Nov. $\left(17^{\circ} \mathrm{C}\right), 2018$. The photosynthetic photon flux was set at
$1000 \mu \mathrm{mol} \cdot \mathrm{m}^{-2} \cdot \mathrm{s}^{-1}$. The third leaves (from the top) on the current-year spring shoots of adult trees and the fifth leaves (from the graft union) of the grafted scions were used as the materials for measurement. Five leaves on each line were selected.

\section{Results}

Plant morphology and karyotype of H39. Height of the 6-year-old tree H39 was only $1.93 \mathrm{~m}$, and diameters of the crown were $2.34 \mathrm{~m}$ (from south to north) and $2.48 \mathrm{~m}$ (from east to west). There were two to four leaves on spring shoots, with only one to three leaves remaining in October. The branches of the tree looked compact (Fig. 1A).

Chromosomes were prepared from shoot tips. At least 20 tips were examined, and 39 chromosomes were observed in all of the shoot tip cells at mitotic metaphase. It was

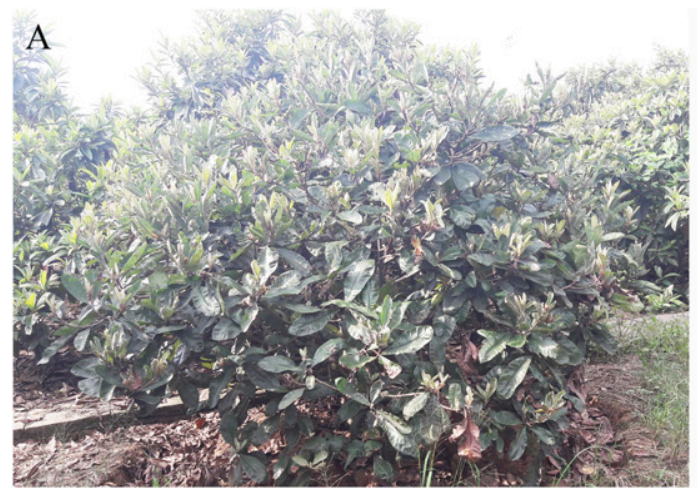

B

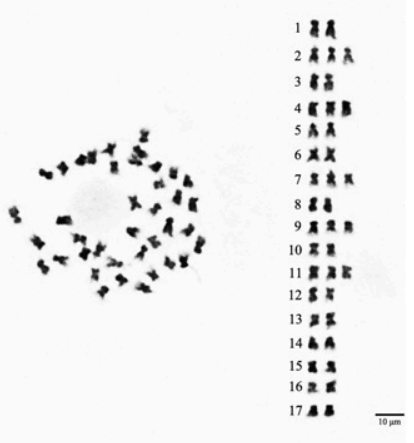

Fig. 1. Plant (A) and karyotype (B) of H39. therefore concluded that the plant line had 39 chromosomes, hence the name H39.

The karyotype of H39 was analyzed. According to the chromosome configuration, it was found that there were five extra chromosome copies in H39 compared with the normal diploid plant. They included one extra copy each for chromosome 2, chromosome 4, chromosome 7, chromosome 9 , and chromosome 11 (Fig. 1B). Chromosome 2 and chromosome 4 had subterminal centromeres, and the remaining three had submetacentric centromeres.

Leaf morphology of H39 adult trees. Leaves of H39 were largely different from those of the diploid ('Ruantiaobaisha') and triploid ('Wuheguoyu') plants. First, the leaf apex of H39 was acute-shaped (Fig. 2B) compared with the acuminate shape of the diploid and triploid (Fig. 2A and C). Second, angles between the midribs and lateral veins on H39 leaves were larger than those of the diploid and triploid plants. Third, mesophylls of H39 were brittle and easily breakable, compared with the relatively strong mesophylls in the diploids and triploids. Fourth, leaf length of H39 was $27.26 \pm 1.69 \mathrm{~cm}$, which was significantly shorter $(P<0.05)$ than those of the diploid and triploid (31.62 \pm $3.16 \mathrm{~cm}$ and $30.38 \pm 1.26 \mathrm{~cm}$, respectively), but leaf width showed the opposite, being smaller for the H39 leaves $(10.82 \pm 0.48 \mathrm{~cm})$ than the diploid and triploid leaves $(9.78 \pm$ $0.74 \mathrm{~cm}, 9.88 \pm 0.51 \mathrm{~cm}$ ) (Table 1). As a result, the length-to-width ratio of $\mathrm{H} 39$ leaves was significantly smaller than those of the diploid and triploid $(P<0.01)$. This made the leaf of H39 blunter and more elliptical (Fig. 2B). Fifth, the leaves of $\mathrm{H} 39$ were much thinner $(P<0.01)$ than those of the diploid and triploid plants, and consequently the unit area biomass of H39 leaves was far smaller (Table 1).

Microscopic visualization of paraffin sections showed that the palisade mesophyll of H39 was much thinner than that of the diploid and triploid plants $(P<0.01)$ (Fig. 3), being only $74.80 \pm 2.12 \mu \mathrm{m}$, in contrast to $218.94 \pm$ $13.83 \mu \mathrm{m}$ in the diploid and $177.85 \pm 5.89 \mu \mathrm{m}$ in the triploid. It was also observed that the palisade mesophyll of the diploid plants had four layers of cells and the triploid had three to four layers, whereas the H39 mesophylls had only one layer of cells. In addition, the wax coat on upper epidermis of H39 was much thinner than that of the diploid and triploid $(P<0.01)$ (Fig. 3), being only $5.49 \pm$ $0.58 \mu \mathrm{m}$ in $\mathrm{H} 39$ in contrast to $12.75 \pm$ $1.20 \mu \mathrm{m}$ in the diploid and $12.02 \pm 0.70 \mu \mathrm{m}$ in the triploid. There were no significant differences in the thicknesses of upper epidermis, lower epidermis, and spongy mesophylls among H39, diploid, and triploid plants.

Fig. 2. Leaf of 'Ruantiaobaisha' (2x) (A), H39 (aneuploid) (B), and 'Wuheguoyu' (3x) (C).

Table 1. Comparison of leaf characteristics of H39 (aneuploid), 'Ruantiaobaisha' ( $2 x)$, and 'Wuheguoyu' ( $3 x$ ) adult trees.

\begin{tabular}{lccccc}
\hline Lines & Length $(\mathrm{cm})$ & Width $(\mathrm{cm})$ & Length-width ratio & Thickness $(\mu \mathrm{m})$ & Biomass in unit area $\left(\mathrm{g} / \mathrm{cm}^{2}\right)$ \\
\hline Ruantiaobaisa $(2 x)$ & $31.62 \pm 3.16 \mathrm{a}^{\mathrm{z}}$ & $9.78 \pm 0.74 \mathrm{~b}$ & $3.21 \pm 0.26 \mathrm{aA}$ & $459.49 \pm 31.74 \mathrm{aA}$ & $2.70 \pm 0.06 \mathrm{aA}$ \\
H39 (aneuploid) & $27.26 \pm 1.69 \mathrm{~b}$ & $10.82 \pm 0.48 \mathrm{a}$ & $2.52 \pm 0.17 \mathrm{bB}$ & $305.80 \pm 23.86 \mathrm{cB}$ & $1.99 \pm 0.06 \mathrm{bB}$ \\
Wuheguoyu (3x) & $30.38 \pm 1.26 \mathrm{a}$ & $9.88 \pm 0.51 \mathrm{~b}$ & $3.08 \pm 0.13 \mathrm{aA}$ & $416.60 \pm 20.43 \mathrm{bA}$ & $2.76 \pm 0.08 \mathrm{aA}$ \\
\hline
\end{tabular}

${ }^{\mathrm{z}}$ Different lowercase letters in the same column indicate significant differences at $P<0.05$. Different capital letters in the same column indicate significant differences at $P<0.01$. 




Fig. 3. Light micrographs $(\times 200)$ of transverse sections of 'Ruantiaobaisha' (A), H39 (B), and 'Wuheguoyu' (C).

Table 2. Comparison of chlorophyll contents in leaves on adult trees of H39, 'Ruantiaobaisha', and 'Wuheguoyu'.

\begin{tabular}{lcccc}
\hline Lines & Chlorophyll a & Chlorophyll b & Total chlorophyll $(\mathrm{a}+\mathrm{b})$ & Carotenoid \\
\hline $\begin{array}{l}\text { Ruantiaobaisa }(2 x) \\
\left(\mathrm{mg} / \mathrm{cm}^{2}\right)\end{array}$ & $5.47 \pm 0.31 \mathrm{aA}^{\mathrm{z}}$ & $2.02 \pm 0.22 \mathrm{~b}$ & $7.49 \pm 0.53 \mathrm{ABb}$ & $0.81 \pm 0.05 \mathrm{aA}$ \\
$\begin{array}{c}\mathrm{H} 39 \text { (aneuploid) } \\
\quad\left(\mathrm{mg} / \mathrm{cm}^{2}\right)\end{array}$ & $4.42 \pm 0.16 \mathrm{bB}$ & $2.11 \pm 0.22 \mathrm{ab}$ & $6.54 \pm 0.39 \mathrm{Bc}$ & $0.42 \pm 0.07 \mathrm{bB}$ \\
$\begin{array}{c}\text { Wuheguoyu }(3 x) \\
\quad\left(\mathrm{mg} / \mathrm{cm}^{2}\right)\end{array}$ & $6.50 \pm 0.70 \mathrm{aA}$ & $2.47 \pm 0.13 \mathrm{a}$ & $8.98 \pm 0.57 \mathrm{Aa}$ & $0.87 \pm 0.18 \mathrm{aA}$ \\
$\begin{array}{llll}\text { Ruantiaobaisa }(2 x)(\mathrm{mg} / \mathrm{g}) \\
\text { H39 (aneuploid) }(\mathrm{mg} / \mathrm{g})\end{array}$ & $2.01 \pm 0.11 \mathrm{~b}^{\mathrm{z}}$ & $0.74 \pm 0.08 \mathrm{~b}$ & $2.75 \pm 0.19 \mathrm{~b}$ & $0.30 \pm 0.02 \mathrm{a}$ \\
Wuheguoyu $(3 x)(\mathrm{mg} / \mathrm{g})$ & $2.28 \pm 0.25 \mathrm{ab}$ & $0.87 \pm 0.04 \mathrm{~b}$ & $3.16 \pm 0.20 \mathrm{ab}$ & $0.31 \pm 0.06 \mathrm{a}$ \\
\hline
\end{tabular}

${ }^{\mathrm{z}}$ Different lowercase letters in the same column indicate significant differences at $P<0.05$. Different capital letters in the same column indicate significant differences at $P<0.01$.

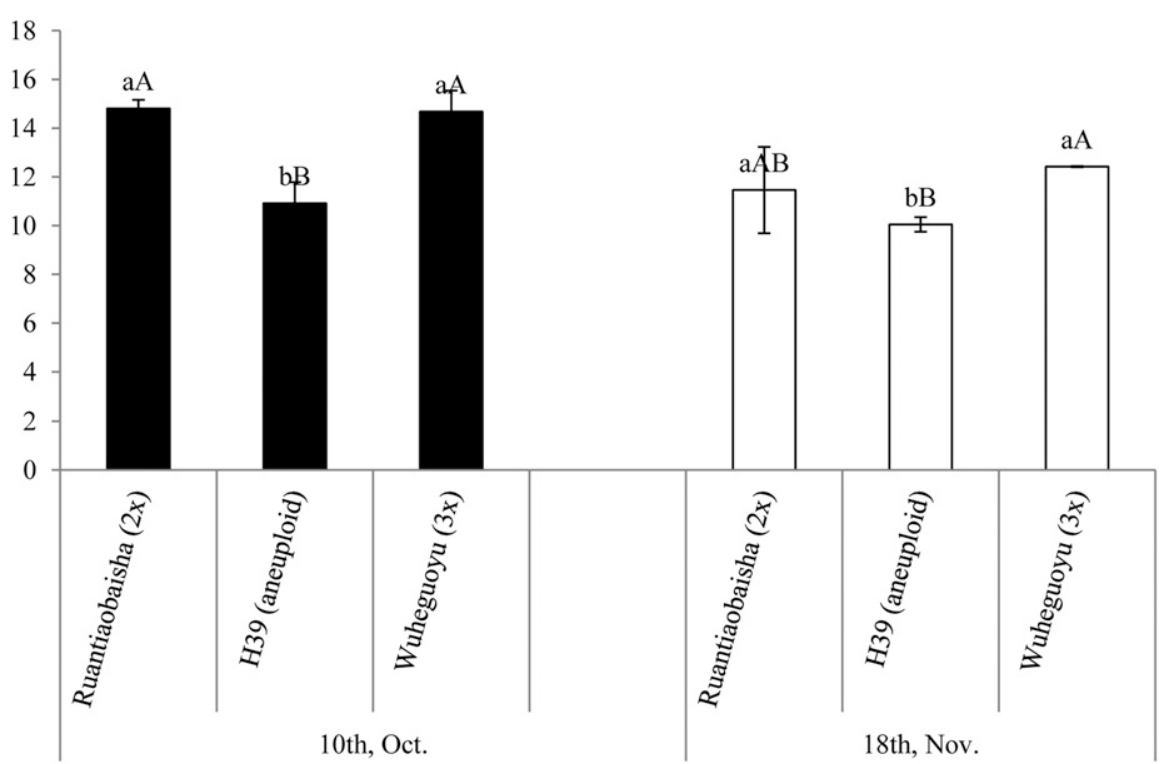

Fig. 4. Net photosynthetic rates of adult trees of the three lines. Different lowercase letters indicate significant differences at $P<0.05$. Different capital letters indicate significant differences at $P<0.01$.

Photosynthetic characteristics of H39 adult trees. Leaf chlorophyll contents in adult trees of the three loquat lines were measured (Table 2). In H39, chlorophyll a content was only $4.42 \pm 0.16 \mathrm{mg} / \mathrm{cm}^{2}$, which was significantly reduced compared with the diploid and triploid lines $(P<0.01)$; the unit area total chlorophyll were near and even some more than those of diploid and triploid, whereas the contents of carotenoid were opposite.

The net photosynthetic rate of $\mathrm{H} 39$, measured on 10 Oct. 2018, was $10.92 \pm 0.86$ $\mu \mathrm{mol} \cdot \mathrm{m}^{-2} \cdot \mathrm{s}^{-1} \quad \mathrm{CO}_{2}$. This was significantly lower $(P<0.01)$ than those of the diploid and triploid, which were $14.81 \pm 0.35$ and $14.68 \pm 0.86 \mu \mathrm{mol} \cdot \mathrm{m}^{-2} \cdot \mathrm{s}^{-1} \mathrm{CO}_{2}$, respectively (Fig. 4). When measured on Nov. 18, 2018, the net photosynthetic rates were reduced in all the three tree lines, but H39 still showed the lowest rate, although with a low significance of difference compared with the diploid (Fig. 4).

Photosynthetic and growth characteristics of scions grafted in the current year. Leaf chlorophyll contents of scions of the tree lines on grafted seedlings were measured (Table 3 ). The differences in chlorophyll and carotenoid contents in leaf area among the grafted scions of the three lines were similar to those in the adult trees. Thus, H39 scions had slightly less chlorophyll and carotenoid contents than the other two lines, but showed slightly more unit leaf biomass except carotenoid. Two repeated measurements showed that the net photosynthetic rates of H39 scions were lower than those of the diploid and triploid scions with strong significance $(P<0.01)$ (Fig. 5).

The scions of the three lines had grown on rootstocks for 8 months. As shown in Table 4 scions of $\mathrm{H} 39$ were $32.84 \pm 5.35 \mathrm{~cm}$ in length, significantly shorter than the diploid (43.82 \pm $1.89 \mathrm{~cm})$ and triploid $(41.28 \pm 1.87 \mathrm{~cm})$ scions $(P<0.01)$. Stems of $\mathrm{H} 39$ scions were $7.53 \pm 1.03 \mathrm{~cm}$ in thickness, slightly thinner than that of the diploid $(8.28 \pm 0.65 \mathrm{~cm})$ but significantly thinner than that of the triploid $(10.65 \pm 0.41 \mathrm{~cm})(P<0.01)$. Internode length of $\mathrm{H} 39$ scions was $1.12 \pm 0.20 \mathrm{~cm}$, significantly shorter than the diploid (1.49 \pm $0.22 \mathrm{~cm})$ and triploid $(1.51 \pm 0.13 \mathrm{~cm})$ scions $(P<0.05)$. Similarly, the leaf length of H39 scions $(18.34 \pm 1.57 \mathrm{~cm})$ was also significantly shorter than that of the diploid (23.08 \pm $0.85 \mathrm{~cm})$ and triploid $(23.16 \pm 3.44 \mathrm{~cm})$ scions $(P<0.05)$. As a whole, the growth of H39 scions on rootstocks was weaker than the diploid and triploid scions.

\section{Discussion}

In general, aneuploidy negatively affects the vigor of plants, and most plants cannot tolerate aneuploidy. Consequently, few aneuploids occur in nature and the gametes of triploid plants mostly abort (Ramsey and Schemske, 1998; Henry et al., 2005). However, some aneuploids can survive and they often exhibit some novel traits (Henry et al., 2010a). In the present study, we identified and characterized an aneuploid loquat line name $\mathrm{H} 39$, which was derived from a triploid tree, and has 39 chromosomes. The haploid chromosome number of loquat is 17 ; therefore, a normal diploid loquat has 34 chromosomes, and triploid 51 chromosomes. The extra five chromosome copies of H39 compared with the diploid progenitor were 
Table 3. Comparison of chlorophyll contents in 8-month scion leaves of H39, 'Ruantiaobaisha', and 'Wuheguoyu'.

\begin{tabular}{|c|c|c|c|c|}
\hline$\overline{\text { Lines }}$ & Chlorophyll a & Chlorophyll b & Total chlorophyll $(\mathrm{a}+\mathrm{b})$ & Carotenoid \\
\hline Wuheguoyu $(3 x)\left(\mathrm{mg} / \mathrm{cm}^{2}\right)$ & $5.83 \pm 0.19 \mathrm{aA}$ & $2.32 \pm 0.11$ & $8.16 \pm 0.30 \mathrm{aA}$ & $0.77 \pm 0.03 \mathrm{aA}$ \\
\hline Ruantiaobaisa $(2 x)(\mathrm{mg} / \mathrm{g})$ & $2.16 \pm 0.14 \mathrm{abAB}^{\mathrm{z}}$ & $0.99 \pm 0.17 \mathrm{abAB}$ & $3.16 \pm 0.31 \mathrm{abAB}$ & $0.24 \pm 0.04 \mathrm{abAB}$ \\
\hline Wuheguoyu $(3 x)(\mathrm{mg} / \mathrm{g})$ & $1.99 \pm 0.07 \mathrm{bB}$ & $0.79 \pm 0.04 \mathrm{bB}$ & $2.79 \pm 0.10 \mathrm{bB}$ & $0.26 \pm 0.01 \mathrm{aA}$ \\
\hline
\end{tabular}

${ }^{\mathrm{z}}$ Different lowercase letters in the same column indicate significant differences at $P<0.05$. Different capital letters in the same column indicate significant differences at $P<0.01$.

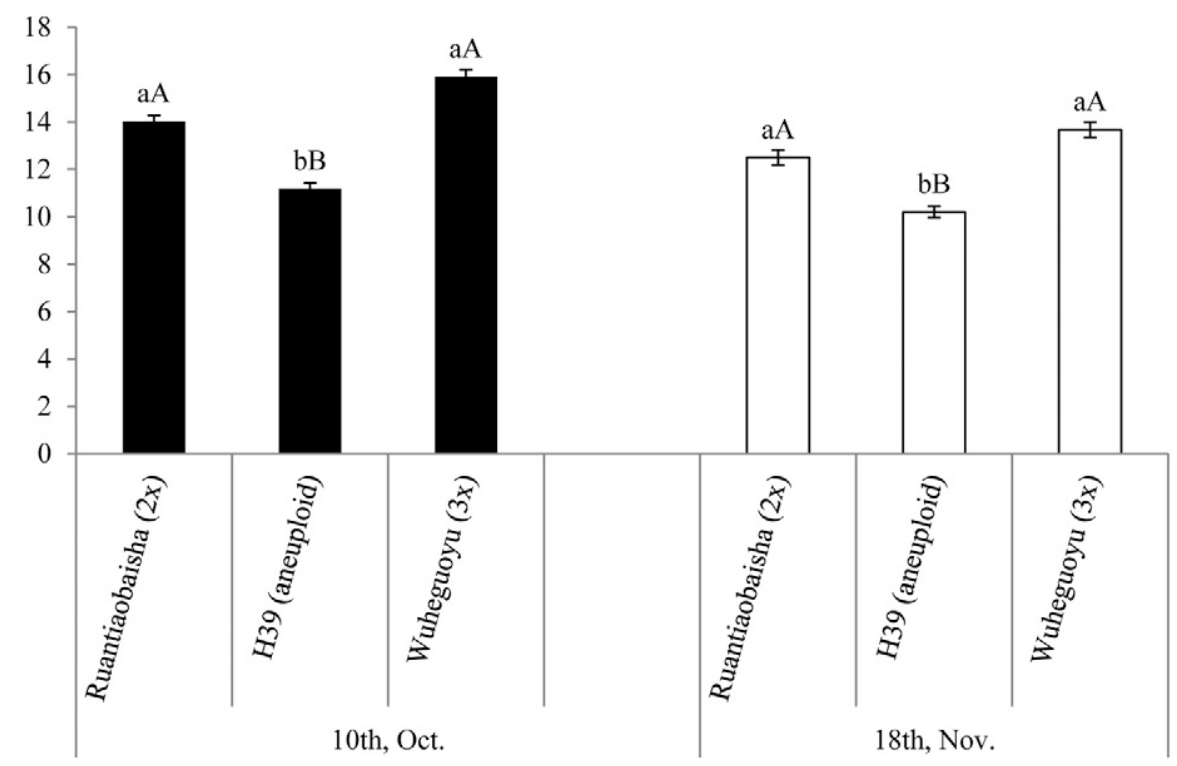

Fig. 5. Net photosynthetic rates of grafted scions of the three lines. Different lowercase letters indicate significant differences at $P<0.05$. Different capital letters indicate significant differences at $P<0.01$.

Table 4. Comparison of 8-month scion morphology of H39, 'Ruantiaobaisha', and 'Wuheguoyu'.

\begin{tabular}{lccccc}
\hline Lines & Ht $(\mathrm{cm})$ & $\begin{array}{c}\text { Stem } \\
\text { thickness }(\mathrm{cm})\end{array}$ & $\begin{array}{c}\text { Internode } \\
\text { length }(\mathrm{cm})\end{array}$ & $\begin{array}{c}\text { Leaf length } \\
(\mathrm{cm})\end{array}$ & $\begin{array}{c}\text { Leaf } \\
\text { width }(\mathrm{cm})\end{array}$ \\
\hline $\begin{array}{l}\text { Ruantiaobaisa } \\
(2 \mathrm{x})\end{array}$ & $43.82 \pm 1.89 \mathrm{aA}^{\mathrm{z}}$ & $8.28 \pm 0.65 \mathrm{bB}$ & $1.49 \pm 0.22 \mathrm{aAB}$ & $23.08 \pm 0.85 \mathrm{aAB}$ & $6.52 \pm 0.30$ \\
& & & & & \\
H39 (aneuploid) & $32.84 \pm 5.35 \mathrm{bB}$ & $7.53 \pm 1.03 \mathrm{bB}$ & $1.12 \pm 0.20 \mathrm{bB}$ & $18.34 \pm 1.57 \mathrm{bB}$ & $6.74 \pm 0.79$ \\
Wuheguoyu (3x) & $41.28 \pm 1.87 \mathrm{aA}$ & $10.65 \pm 0.41 \mathrm{aA}$ & $1.51 \pm 0.13 \mathrm{aA}$ & $23.16 \pm 3.44 \mathrm{aA}$ & $6.76 \pm 0.47$ \\
\hline $\begin{array}{l}\text { zifferent lowercase letters in the same column indicate significant differences at } P<0.05 . \text { Different } \\
\text { capital letters in the same column indicate significant differences at } P<0.01 .\end{array}$
\end{tabular}

attributed to one additional copy each of chromosomes 2, 4, 7, 9, and 11 .

A study in $A$. thaliana by Henry et al. (2010a) showed that certain traits are strongly associated with the dosage of specific chromosome types and that such chromosomal effects can be additive. Imbalanced gene expression usually occurs in aneuploid plants presumably due to the abnormal chromosome numbers (Huettel et al., 2008). Such changes in gene dosage are likely to be associated with the specific phenotypes found in aneuploid plants. However, so far there has been no study focusing on the gene expression analysis of aneuploid fruit trees with novel traits. H39 could potentially be used to study the link between gene dosages and phenotypic traits. In addition, the characterization of the chromosomal structure of H39 provides an opportunity to map novel traits to specific chromosome types.
H39 was shown to have a number of novel traits compared with the diploid and triploid progenitors, including increased leaf width, reduced thickness of leaf palisade mesophyll and wax coat, decreased chlorophyll content and photosynthesis rates, and overall reduction in growth. These phenotypic differences occurred in both mature plants and in young grafted scions. Photosynthesis is the only assimilation process in plants, and lower photosynthetic efficiency would lead to slower growth. The stunted growth of the $\mathrm{H} 39$ scions could therefore be attributed to its reduced photosynthesis rates compared with the diploid and triploid plants. Studies on 14 grass species showed that $\mathrm{CO}_{2}$ assimilation rate per unit leaf area was positively correlated with leaf thickness and with the amount of mesophyll per unit leaf area (Garnier et al., 2010). Leaf thickness and chlorophyll contents per unit leaf area were both reduced in
H39 compared with diploid and triploid, and this could explain the reduced photosynthetic efficiency of $\mathrm{H} 39$.

Slow growth rates can be used in plant dwarfing. Aneuploid guava plants have previously been studied in relation to rootstock selection for dwarfing (Feungehum, 1975). An aneuploid guava line No. 82 was verified to be a substantial dwarfing rootstock without yield reduction (Sharma et al., 1992). In pears, some dwarfing rootstocks were found to be aneuploids (Simard and Demilly, 2005), and dwarfing in Pyrus was found to be linked with an aneuploid chromosomal structure found in hybrids between a triploid genotype of $P$. nivalis and a diploid one of the Pyrus species (Simard et al., 2011). Loquat is a type of fruit tree with a relatively large size, and dwarf plants are urgently needed to help reduce labor cost in loquat production. The identified aneuploid H39 could be used as a potential germplasm for breeding dwarfing rootstocks or interstocks. Rootstock and interstock test on $\mathrm{H} 39$ will be carried out in the near future.

\section{Literature Cited}

Badenes, M.L. and D.H. Byrne (eds.). 2012. Fruit breeding. Springer, Boston, MA.

Chagné, D., C. Kirk, C. Whitworth, S. Erasmuson, R. Bicknell, D.J. Sargent, S. Kumar, and M. Troggio. 2015. Polyploid and aneuploid detection in apple using a single nucleotide polymorphism array. Tree Genet. Genomes 11:1-6.

Chen, R.Y., W.Q. Song, and L. Li. 1979. A new method for preparing mitotic chromosomes from plants. Acta Bot. Sin. 21:297-298.

Ezura, H., I. Kikuta, and K. Oosawa. 1994. Production of aneuploid melon plants following in vitro culture of seeds from a triploid $\times$ diploid cross. Plant Cell Tissue Organ Cult. 38:61-63.

Feungehum, S. 1975. Growth potential of aneuploid guava (Psidium guaiava L.) in relation to rootstock selection. New Delhi: Indian Agricultural Research Institute (IARI), Division of Fruits and Horticultural Technology.

Garnier, E., J.L. Salager, G. Laurent, and L. Sonie. 2010. Relationships between photosynthesis, nitrogen and leaf structure in 14 grass species and their dependence on the basis of expression. New Phytol. 143:119-129.

Henry, I.M., B.P. Dilkes, K. Young, B. Watson, H. $\mathrm{Wu}$, and L. Comai. 2005. Aneuploidy and genetic variation in the Arabidopsis thaliana triploid response. Genetics 170:1979-1988.

Henry, I.M., B.P. Dilkes, A.P. Tyagi, H.Y. Lin, and L. Comai. 2009. Dosage and parent-of-origin effects shaping aneuploid swarms in Arabidopsis thaliana. Heredity 103:458-468.

Henry, I.M., B.P. Dilkes, E.S. Miller, D. BurkartWaco, and L. Comai. 2010a. Phenotypic consequences of aneuploidy in Arabidopsis thaliana. Genetics 186:1231-1245. 
Henry, I.M., B.P. Dilkes, and L. Comai. 2010b. Molecular karyotyping and aneuploidy detection in Arabidopsis thaliana using quantitative fluorescent polymerase chain reaction. Plant J. 48:307-319.

Huettel, B., D.P. Kreil, M. Matzke, and A.J. Matzke. 2008. Effects of aneuploidy on genome structure, expression, and interphase, organization in, Arabidopsis thaliana. PLoS Genet. 4:E1000226.

Kikuchi, S., M. Iwasuna, A. Kobori, Y. Tsutaki, A. Yoshida, Y. Murota, E. Nishino, H. Sassa, and T. Koba. 2014. Seed formation in triploid loquat (Eriobotrya japonica) through crosshybridization with pollen of diploid cultivars. Breed. Sci. 64:176-182.

Lichtenthaler, H.K. 1987. Chlorophylls and carotenoids: Pigments of photosynthetic biomembranes. Methods Enzymol. 148:350 382.

Mohammed, S. 1974. Aneuploidy in guava. Biol. Plant. 16:382-388.
Park, S.M., M. Hiramatsu, and A. Wakana. 1999. Aneuploid plants derived from crosses with triploid grapes through immature seed culture and subsequent embryo culture. Plant Cell Tissue Organ Cult. 59:125-133.

Ramsey, J. and D.W. Schemske. 1998. Pathways, mechanisms and rates of polyploid formation in flowering plants. Annu. Rev. Ecol. Syst. 29: 467-501.

Sharma, Y.K., A.M. Goswami, and R.R. Sharma 1992. Effect of dwarfing aneuploid guava rootstock in high density orcharding. Indian J. Hort. 49:31-36.

Simard, M.H. and D. Demilly. 2005. Ploidy level evaluation of rootstock selections and Pyrus genus accessions. Acta Hort. 671:267-273.

Simard, M.H., R. Guisnel, F. Daguin, D. Demilly, B. Billy, and D. Honoré. 2011. Is dwarfing in pear rootstocks due to aneuploid genetic structures? XI Int. Pear Symp. 909:59-66.

Vogt, G.E. and P.R. Rowe. 2011. Aneuploids from triploid-diploid crosses on the series
Tuberosa of the genus Solanum. Genome 10:479-486.

Yasuda, K., M. Yahata, H. Komatsu, Y. Kurogi, and H. Kunitake. 2010. Triploid and aneuploid hybrids from diploid-diploid intergeneric crosses between Citrus cultivar 'Kiyomi' tangor and Meiwa kumquat (Fortunella crassifolia swingle) for seedless breeding of kumquats. J. Jpn. Soc. Hort. Sci. 79:16-22.

Zhang, C.H. and S.M. Park. 2010. Growth and fruit characteristics of aneuploid apple obtained from crosses between diploid and triploid. J. Bio-Environ. Control 18:481-491.

Zhang, C.H. and P. Sungmin. 2009. Aneuploid production from crosses with diploid and triploid in apple tree. Hort. Environ. Biotechnol. 50:203-207.

Zhuang, D.H., Y. Qu, D.X. Xu, J. Li, and Z.L. Chen. 2007. Analysis on chromosome number and morphology of varieties in Phalaenopsis. Acta Horticulturae Sinica 34:1257-1262 (in Chinese with English abstract). 